\title{
Evidence for a role of geranylgeranylation in renal angiomyolipoma and renal epithelioid angiomyolipoma
}

\author{
DAN-DAN ZHAO ${ }^{1,2^{*}}$, JUN YUAN $^{3 *}$, QI CHENG $^{1}$, YA-LING QI $^{1}, \mathrm{KE} \mathrm{LU}^{1}$, SHAN-SHAN LAI $^{4}$, QIAN SUN ${ }^{1}$,

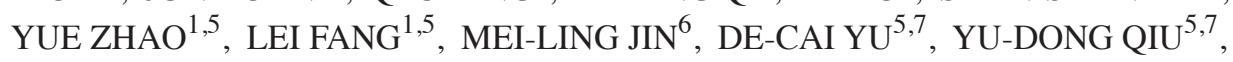 \\ CHAO-JUN LI ${ }^{1}$, JUN CHEN ${ }^{5,8}$ and BIN XUE ${ }^{1,5,9}$
}

${ }^{1}$ State Key Laboratory of Pharmaceutical Biotechnology and Jiangsu Key Laboratory of Molecular Medicine and
School of Medicine, Nanjing University, Nanjing, Jiangsu $210093 ;{ }^{2}$ Research Center, Shanghai Chest Hospital,
Shanghai Jiao Tong University, Shanghai 200030; ${ }^{3}$ Biochemical and Environmental Engineering School of
Xiaozhuang College, Nanjing 211171; Jiangsu Key Laboratory for Biodiversity and Biotechnology,
College of Life Sciences, Nanjing Normal University, Nanjing, Jiangsu $210023 ;{ }^{5}$ Liver Disease Collaborative
Research Platform of Medical School of Nanjing University, Nanjing, Jiangsu $210093 ;{ }^{6}$ Pulmonary Department,
Zhongshan Hospital, Fudan University, Shanghai 200032; Departments of ${ }^{7}$ Hepatobiliary Surgery and
${ }^{8}$ Pathology, The Affiliated Drum Tower Hospital, Medical School of Nanjing University, Nanjing, Jiangsu 210008;
${ }^{9}$ State Key Laboratory of Natural Medicines, China Pharmaceutical University, Nanjing, Jiangsu 210009, P.R. China

Received March 4, 2018; Accepted October 19, 2018

DOI: $10.3892 / 01.2018 .9808$

\begin{abstract}
Research on mevalonate kinase deficiency has revealed that it may lead to the development of renal angiomyolipomas (RAMLs). Thus, it was suspected that geranylgeranyl pyrophosphate synthase (GGPPS), a key enzyme in the mevalonate pathway, may be involved in the development of RAMLs. In the present study, the expression of GGPPS in RAMLs and renal epithelioid angiomyolipomas (REAs) was assessed, and paraffin embedded specimens from 60 patients, including 9 cases with REA and 51 cases with RAML, were examined. Immunoreactivity was evaluated semi-quantitatively according to the intensity of staining and the percentage of positively stained cells. The results indicated that GGPPS was predominantly present in the cytoplasm, and
\end{abstract}

Correspondence to: Professor Bin Xue, State Key Laboratory of Pharmaceutical Biotechnology and Jiangsu Key Laboratory of Molecular Medicine and School of Medicine, Nanjing University, 22 Hankou Road, Nanjing, Jiangsu 210093, P.R. China

E-mail: xuebin@nju.edu.cn

Dr Jun Chen, Department of Pathology, The Affiliated Drum Tower Hospital, Medical School of Nanjing University, Building 1, 321 Zhongshan Road, Nanjing, Jiangsu 210008, P.R. China

E-mail: ichenjun@qq.com

*Contributed equally

Key words: renal angiomyolipoma, mammalian target of rapamycin, renal epithelioid angiomyolipomas, geranylgeranyl pyrophosphate synthase
REA tissues exhibited higher expression of GGPPS in the cytoplasm compared with RAML tissues. It was also identified that GGPPS was upregulated in TSC2-null cells, and inhibition of GGPPS could induce apoptosis of TSC2-null cells by autophagy. In conclusion, the increased expression of GGPPS in RAMLs and REAs indicated that mevalonate pathways may be involved in disease progression. GGPPS may serve as a potential therapeutic target and the current results may provide a novel therapeutic strategy for RAML and lymphangioleiomyomatosis.

\section{Introduction}

Research on mevalonate kinase deficiency has revealed that it may predispose patients to the development of renal angiomyolipomas (RAMLs) (1). RAMLs are benign tumors of the kidney, composed of blood vessels, smooth muscle cells and adipose tissues. RAMLs account for 2.0-6.4\% of all renal tumors. RAML is associated with pain, hematuria, retroperitoneal hemorrhage and mortality. RAMLs require active intervention if the tumor size increases with time $(2,3)$. Despite the benign nature of RAMLs, nephron-sparing surgery is the preferred treatment modality (4-6).

Renal epithelioid angiomyolipomas (REAs) comprise approximately $7.7 \%$ of RAMLs (7). There is considerable evidence indicating that REA is a malignant disease and tumor metastasis usually occurs following surgery (8). Notably, there is no effective clinical drug for REA $(9,10)$.

Recently, analysis of the genetic basis of angiomyolipoma(AML) developmenthasrevealed that lossof heterozygosity in the tuberous sclerosis 2 (TSC2) regions is present in certain AMLs, with no evidence of other genetic alterations (11). Therefore, the phosphoinositide 3-kinase/AKT/mammalian target of rapamycin (mTOR) pathways have been suggested 
to be involved in the occurrence and development of AMLs. Previous research by our group demonstrated that geranylgeranyl pyrophosphate synthase (GGPPS) deletion may upset the balance of protein farnesylation and geranylgeranylation and influence the mTOR signaling pathway $(12,13)$. Additionally, it has been reported that inhibition of geranylgeranylation of the small Rho GTPase proteins by statins or bisphosphonates may block the mTOR pathway and lead to TSC2-null cell apoptosis (14). Furthermore, geranylgeranyl pyrophosphate (GGPP) may preserve prostate cancer cell autophagy and decrease the migration of breast cancer cells via bisphosphonates $(15,16)$. Therefore, it was hypothesized that the mevalonate pathway and geranylgeranylation could play an important role in the mTOR pathway in RAML tumor progression.

GGPPS is a key enzyme in the mevalonate pathway that is responsible for GGPP synthesis and that utilizes farnesylpyrophosphate (FPP) to produce GGPP. GGPPS balances the prenylation of $\mathrm{G}$ proteins in cells (17). However, the function of GGPPS in the progression of RAML is unknown.

The aim of the present study was to distinguish the different pathogeneses of REA and RAML by evaluating the expression of GGPPS. A total of 60 cases with clinical and pathological characteristics of RAMLs were included, and the association between GGPPS expression and the progression of RAMLs and REAs was investigated. To validate the association, it was identified in in vitro studies that GGPPS was upregulated in mouse TSC2-null cells and inhibition of GGPPS markedly induced apoptosis of TSC2-null cells by autophagy.

\section{Patients and methods}

Patients. A total of 60 patients, including 9 cases with REA and 51 cases with RAML, were recruited at the Department of Pathology of Nanjing Drum Tower Hospital (Nanjing, China) from June 2013 to December 2015. RAML, REA and malignant REA were pathologically diagnosed according to the 2004 WHO classification $(18,19)$. A total of 48 patients were included in the follow-up. All specimen collection procedures were approved by Nanjing Drum Tower Hospital (Nanjing, China). All procedures involving human participants were in accordance with the ethical standards of the Independent Ethic Committee of Nanjing Drum Tower Hospital (Nanjing, China) and with the 1964 Declaration of Helsinki and its later amendments or comparable ethical standards. Informed consent was obtained from all individual participants included in the study.

Immunohistochemistry. All RAML and REA tissue samples were processed according to standard methods. Briefly, 4- $\mu \mathrm{m}$-thick slices were dewaxed in xylene and graded concentrations of alcohol, and hydrated and washed in PBS. To eliminate interference from blood cells, endogenous peroxidase was inhibited with $3 \%$ hydrogen peroxide in $\mathrm{dH}_{2} \mathrm{O}$ for $15 \mathrm{~min}$. Then, heat-mediated antigen retrieval was performed on the deparaffinized sections using a citrate buffer $(10 \mathrm{mmol} / 1$ sodium citrate buffer, $\mathrm{pH}=6$ ) for $10 \mathrm{~min}$ in a microwave oven prior to incubation with the primary antibodies, and this process was followed by avidin-biotin blocking using goat serum (Beyotime Institute of Biotechnology, Haimen, China). The slices were then immunoassayed with antibodies against Ki-67 (1:400; cat. no. RM-9106-S) and Melanoma (gp100)
Ab-1 (clone HMB45; 1:80; cat. no. MS-364-S; both from NeoMarkers, Inc., Fremont, CA, USA), SMA (ASM-1; dilution, 1:250; cat. no. SMA-L-CE; Leica Biosystems Newcastle Ltd., Newcastle, UK), Desmin (clone D33; 1:100; cat. no. M0760) and S100 (dilution, 1:5,000; cat. no. S100), Melan A (clone A103; dilution, 1:100; cat. no. IS63330-2 ) both from Dako; Agilent Technologies, Inc. Santa Clara, CA, USA), human GGPPS (E1; 1:200; cat. no. 14944-1-AP; ProteinTech Group, Inc., Chicago, IL, USA) and p-S6ser235/236 (1:200; cat. no. 4858; Cell Signaling Technology, Inc., Danvers, MA, USA). Then, the slices were incubated with a bio-free horseradish peroxide-labeled polymer from an EnVision plus detection system (cat. no. K500711-2; Dako; Agilent Technologies, Inc.) for $1 \mathrm{~h}$ at room temperature. The positive immunoreactions were revealed with diaminobenzidine solution, and in the negative control samples, the primary antibodies were replaced with non-immune goat serum (cat. no. C0265; Beyotime Institute of Biotechnology). Stained slices from all cases were reviewed by at least two histopathologists, and the original diagnoses were confirmed. The nuclear immunoreactivity for $\mathrm{Ki}-67$ and the cytoplasmic staining for HMB45, SMA, S100, Desmin, GGPPS and p-S6 were evaluated semi-quantitatively according to staining intensity and the percentage of positive cells. The percentage of positive tumor cells was graded as follows: 0 , none; $1,1-25 \% ; 2,26-50 \% ; 3$, 51-75\%; and 4, 76-100\%. The immunostaining intensity was scored as follows: 0 , none; 1 , week; 2 , moderate; and 3 , intense. Thus, the total scores for Ki-67, HMB45, SMA, S100, Desmin, GGPPS, and p-S6 are provided as the sum of the percentage of positive tumor cells and the immunostaining intensity. The total scores $0(-)$ were negative scores, and $2(+) ; 3$ and $4(++)$; 5-7 (+++) were positive scores $(18,20)$.

Immunofluorescence. Cells were grown on chamber slices (EMD Millipore, Billerica, MA, USA), harvested 3 days after siRNA transfection (described below), fixed in $100 \%$ cold methanol, blocked in $10 \%$ goat normal serum, $1 \%$ BSA and $0.1 \%$ Triton X-100/PBS, and incubated with the following antibodies: LAMP1 (dilution, 1:100; cat. no. sc-19992; Santa Cruz Biotechnology, Inc., Dallas, TX, USA) and LC3 (dilution, 1:100; cat. no. ab167159; Abcam, Cambridge, MA, USA). Alexa Fluor 488- (1:200; cat. no. ab150073) or Alexa Fluor 594-conjugated secondary antibodies (1:200; cat. no. ab150140; Abcam) were used and DNA was stained with DAPI within the mounting medium (cat. no. ab104139; Abcam).

Cell culture and reagents. TSC2-wt cells and TSC2-null cells were kindly donated by Dr John Blenis (Weill Cornell Medical College, New York, NY, USA) and were cultured in Dulbecco's modified Eagle's medium (Hyclone; GE Healthcare Life Sciences, Logan, UT, USA) with $10 \%$ fetal bovine serum (Biological Industries, Bat Haemek, Israel) and $1 \%$ penicillin/streptomycin (Sigma-Aldrich; Merck KGaA, Darmstadt, Germany). All cells were cultured at $37^{\circ} \mathrm{C}$ and $5 \% \mathrm{CO}_{2}$. Small interfering RNA (siRNA) oligonucleotides targeting GGPPS were designed and synthesized by (Nanjing Wisdom Biotech Co., Ltd., Nanjing, China). The sequence was as follows: mouse siGGPPS: 5'-GGTGTCCCATCT GTCATTA-3'. The scramble sequence used as a control was as follows: 5'-TTCTCCGAACGTGTCACGT-3'. For RNA 
interference experiments, $1 \times 10^{5}$ cells/well were seeded in a 6-well plate, cultured overnight, then transfected with small interfering (si)RNAs targeting GGPPS and control siRNAs using Lipofectamine RNAiMAX transfection reagent (Invitrogen; Thermo Fisher Scientific, Inc., Waltham, MA, USA). Cells were harvested 3 days after siRNA transfection for apoptosis detection and immunoblotting.

Cell viability and migration. Assessment of viability, migration of TSC2-wt and TSC2-null cells using the Real-Time Cell Analyzer (RTCA; ACEA Biosciences Inc., San Diego, CA, USA). RTCA Software Package 1.2 was used to calibrate the plates. Cells were plated at a density of 1,000/well with fresh medium to a final volume of $200 \mu \mathrm{l}$. Cells were incubated at $37^{\circ} \mathrm{C}$ and $5 \% \mathrm{CO}_{2}$ in the RTCA cradle. The impedance signals were recorded every $12 \mathrm{~h}$ for 6 scans until the end of the experiment (up to $96 \mathrm{~h}$ for proliferation and up to $84 \mathrm{~h}$ for migration).

Immunoblotting. Cells were lysed in radioimmunoprecipitation assay buffer (cat. no. P0013B; Beyotime Institute of Biotechnology, Shanghai, China) with complete protease inhibitor cocktail and phosSTOP phosphatase inhibitor cocktail (Roche Diagnostics, Basel, Switzerland). The protein concentration was detected by the bicinchoninic acid assay (cat. no. KGPBCA; Nanjing KeyGen Biotech Co., Ltd., Nanjing, China). Each sample contained $30 \mu \mathrm{g}$ protein per $15 \mu \mathrm{l}$ and were mixed with loading buffer (cat no. KGP101; Nanjing KeyGen Biotech Co., Ltd.). Protein extracts were resolved by 10 or $15 \%$ SDS-PAGE, transferred to polyvinylidene difluoride (PVDF) membranes (cat. no. 3010040001, Roche Applied Science, Mannheim, Germany). Following soaking in PBS with $5 \%$ non-fat dry milk for $1 \mathrm{~h}$ at $37^{\circ} \mathrm{C}$. The membranes were subsequently incubated at $4^{\circ} \mathrm{C}$ overnight with the following primary antibodies: p-mTOR (1:1,000; cat. no. 2971), mTOR (1:1,000; cat. no. 2972), p-P70S6K (1:1,000; cat. no. 9208), P70S6K (1:1,000; cat. no. 2708), S6 (1:1,000; cat. no. 2317), p62 (1:1,000; cat. no. 39749), p-S6 (1:1,000; cat. no. 4858), caspase-3 (1:1,000; cat. no. 9662), cleaved caspase-3 (1:1,000; cat. no. 9661) (all purchased from Cell Signaling Technology, Inc.). The GGPPS antibody (1:500; cat. no. sc-271679) was obtained from Santa Cruz Biotechnology, Inc. and the LC3 antibody (1:1,000; cat. no. ab167159) was purchased from Abcam. The tubulin antibody (1:2,000; cat. no. BS1699) was obtained from Bioworld Technology, Inc. (St. Louis Park, MN, USA). Membranes were washed with PBST (PBS $+0.5 \%$ Tween-20). Subsequently, the membrane was incubated at $37^{\circ} \mathrm{C}$ for $1 \mathrm{~h}$ with the horseradish peroxidase-conjugated secondary antibody. The bands were visualized using a chemiluminescence procedure (cat. no. WBKLS0500; Merck KGaA, Darmstadt, Germany) and images were captured using a ChemiDoc ${ }^{\mathrm{TM}}$ XRS imaging system (Bio-Rad Laboratories, Inc., Hercules, CA, USA), according to the manufacturer's protocols. These were analyzed using Image Lab 5.0 software (Bio-Rad Laboratories, Inc.).

Flow cytometry. Samples were stained with Annexin V-FITC, $\mathrm{PI}$ in Annexin V binding buffer [Annexin V-FITC/PI Apoptosis Detection kit (cat. no. BD556547; BD Biosciences, Franklin Lakes, NJ, USA)] for $10 \mathrm{~min}$ at room temperature and immediately placed on ice before analysis on a BD FACSCanto flow cytometer, with the data analyzed by FlowJo software (Treestar Inc., Ashland, OR, USA). Three time repeats of this experiment were performed.

Statistical analysis. Data analysis was performed with SPSS 17.0 software (SPSS, Inc., Chicago, IL, USA). Data are presented as the mean \pm standard error of the mean. Student's t-test was performed to compare groups. Tumor fat content was compared with an independent-sample non-parametric test and expressed as the median. The prognostic markers, nuclear atypia, mitosis and necrosis were compared with a Chi-square test. All tests were two-tailed, and $\mathrm{P}<0.05$ was considered to indicate a statistically significant difference.

\section{Results}

Clinicopathological characteristics of patients with RAMLs and REAs. According to the presence of epithelioid cells in RAMLs, 60 patients were divided into two groups. The REA group consisted of 9 patients (5 males and 4 females) with epithelioid cells, and the RAML group consisted of 51 patients (9 males and 42 females) without epithelioid cells. The clinicopathological features of patients are summarized in Table I. The incidence of REAs in all resected RAMLs was $15 \%$. The mean age of the REA group was $42.67 \pm 13.75$ years, the mean tumor size was $6.41 \pm 2.75 \mathrm{~cm}$ (range, $1.50-12.00 \mathrm{~cm}$ ) and the tumor fat content was $0 \pm 5.16 \%$. The mean age of the RAML group was $47.31 \pm 12.84$ years (range, $22-74$ years), the mean tumor size was $6.78 \pm 6.66 \mathrm{~cm}$ (range, $1.50-43.00 \mathrm{~cm}$ ) and the tumor fat content was $40 \pm 36.86 \%$. The mean tumor fat content of the RAML group was higher compared with the RAE group $(0 \pm 5.16 \% ; \mathrm{P}<0.001)$. Microscopic necrosis was observed in $8 \%$ of the RAMLs and $22 \%$ of the REAs.

To further confirm the lesions with epithelioid cells, the tumor cells were immunoassayed for their pathological characteristics. REA lesions were negative for S100 $(\mathrm{P}<0.001)$ and Desmin $(\mathrm{P}=0.024)$ and significant differences were observed between the two groups. The immunohistochemical results revealed positive staining for Melanoma (gp100) Ab-1 (clone HMB45; $\mathrm{P}=0.388)$, Ki-67 ( $\mathrm{P}=1.000)$, Melan A ( $\mathrm{P}=0.571)$, SMA $(\mathrm{P}=0.421)$ and $\mathrm{p}-\mathrm{S} 6(\mathrm{P}=0.163)$, with no significant differences between the REA and RAML groups (Table I). The tumor cells in RAMLs and REAs were positive for Ki-67 (Fig. 1), which was not consistent with previous findings in which epithelioid angiomyolipomas (EAMLs) were strongly positive for Ki-67 while RAMLs were completely negative $(21,22)$.

GGPPS is associated with the pathological characteristics of REAs. To further assess the mTOR pathway activation status in angiomyolipomas, $\mathrm{p}-\mathrm{S} 6$ expression was examined in RAML and REA lesions. The results indicated that 44 were positive and 7 were negative in terms of immunoreactivity with p-S6 in the RAML group. In the REA group, 7 cases were $\mathrm{p}$-S6-positive and 2 cases were $\mathrm{p}$-S6-negative.

Next, GGPPS expression was evaluated in the cytoplasm of tumor cells and it was revealed that certain REAs exhibited variable cytoplasm-positive staining (Fig. 1). GGPPS-positive staining primarily occurred in blood vessels, smooth muscle cells and fat cells. There was a significant difference between the RAML and REA groups $(\mathrm{P}=0.011)$. 
Table I. Detailed clinicopathological characteristics of the RAMLs and REAs.

\begin{tabular}{lccc}
\hline Variables & RAMLs (n=51) & REAs (n=9) & P-value \\
\hline Age & $47.31 \pm 12.84$ & $42.67 \pm 13.75$ & 0.326 \\
Tumor size (cm) & $6.78 \pm 6.66$ & $6.41 \pm 2.75$ & 0.880 \\
Gender & & & $0.002^{\mathrm{a}}$ \\
Female & $42(82 \%)$ & $4(44 \%)$ & \\
Male & $9(18 \%)$ & $5(56 \%)$ & \\
Fat $(\%)$ & $40 \pm 36.86$ & $0 \pm 5.16$ & $<0.001^{\mathrm{b}}$ \\
Necrosis & $4(8 \%)$ & $2(22 \%)$ & 0.259 \\
Tumor location & & & 1.000 \\
Left & $23(45 \%)$ & $4(44 \%)$ & \\
Right & $24(47 \%)$ & $5(56 \%)$ & \\
Both & $4(8 \%)$ & $0(0 \%)$ & \\
Cell atypia & $5(9 \%)$ & $3(33 \%)$ & 0.238 \\
Mitotic figure & $1(2 \%)$ & $1(11 \%)$ & 0.255 \\
HMB45-positive & $44(86 \%)$ & $7(78 \%)$ & 0.388 \\
Ki67-positive & $49(96 \%)$ & $8(87 \%)$ & 1.000 \\
Melan A-positive & $43(84 \%)$ & $9(100 \%)$ & 0.571 \\
SMA-positive & $48(94 \%)$ & $8(87 \%)$ & 0.421 \\
S100-positive & $47(92 \%)$ & $2(22 \%)$ & $<0.001^{\mathrm{c}}$ \\
Desmin-positive & $38(75 \%)$ & $2(22 \%)$ & $0.024^{\mathrm{a}}$ \\
p-S6-positive & $44(86 \%)$ & $7(78 \%)$ & 0.163 \\
GGPPS-positive & $21(41 \%)$ & $8(89 \%)$ & $0.011^{\mathrm{a}}$ \\
\hline & & & \\
\hline
\end{tabular}

The comparisons of the general information, i.e., age and tumor size, between the two groups were performed using independent-sample t-tests. Fat content was compared with an independent-sample non-parametric test and is expressed with the median, and the other prognostic markers, nuclear atypia, mitosis and necrosis were compared with a Chi-square test. All tests were two-tailed, and the significance level was set at a $\mathrm{P}$-value ${ }^{\mathrm{a}} \mathrm{P}<0.05$, ${ }^{\mathrm{b}} \mathrm{P}<0.01$ and ${ }^{\mathrm{C}} \mathrm{P}<0.001$; RAMLs, renal angiomyolipomas; REAs, renal epithelioid angiomyolipomas; GGPS, geranylgeranyl pyrophosphate synthase.

Among the 9 REA cases, 8 were positive for GGPPS and the mean immunoreactivity was 1.78 (8/9 cases exhibited immunoreactivities $\geq 2$; Table II). Among the 9 REA cases, 7 were positive for p-S6 and the mean immunoreactivity was 1.11 (3/9 cases exhibited immunoreactivities $\geq 2$; Table II). Among the 9 REA cases, 8 were positive for Ki-67 and the mean immunoreactivity for Ki-67 was 0.89 (8/9 cases exhibited immunoreactivity=1; Table II). The mean immunoreactivity for GGPPS was greater compared with p-S6 and Ki-67, and the difference in immunohistochemical expression of GGPPS between the RAML and REA groups was significant $(\mathrm{P}=0.011$; Table I). We also examined the association between GGPPS and clinical characteristics of renal angiomyolipomas, but did not find a correlation between GGPPS and patient age, tumor size, and fat (data not shown).

GGPPS is upregulated in TSC2-null cells and inhibition of GGPPS may induce TSC2-null cell apoptosis. Immunohistochemical staining indicated that GGPPS was upregulated in the RAML and REA groups. These results indicated that activation of the mTOR pathway may induce accumulation of GGPPS. To ascertain this hypothesis, the protein level of GGPPS was evaluated in TSC2-wt and TSC2-null cells. A previous study revealed that TSC2-null tumors had marked p-S6 levels compared to TSC2-wt cells (23), and our result concerning p-S6 was consistent with this study. The activation of mTOR was assessed by p-S6 and p-P70S6K and an increase of GGPPS protein was observed in TSC2-null cells, which was consistent with the data from patients (Fig. 2A). The proliferation of TSC2-null cells was inhibited by GGPPS knockdown, however TSC2-wt cells were not affected (Fig. 2B). TSC2-wt and TSC2-null cell migration were both sensitive to GGPPS protein levels (Fig. 2C). Finally, to determine whether TSC2-null cell proliferation was influenced by cell apoptosis, flow cytometry analysis was performed. As expected, TSC2-null cells transfected with siRNA targeting GGPPS exhibited increased apoptosis in comparison with control cells (Fig. 2D). Since TSC1/TSC2 gene mutant cells impaired autophagic flux (24), it was proposed that the inhibition of geranylgeranylation may lead to apoptosis by autophagy. Thus, GGPPS expression by siRNA for 3 days in TSC2-null cells was inhibited, which led to the accumulation of the lysosomal marker LAMP1 and the marker of autophagosome LC3 (Fig. 2E). Notably, increased cleaved caspase-3 was also detected following inhibition of GGPPS in TSC2-null cells and the mTOR signaling pathway was inhibited leading to autophagy of TSC2-null cells (Fig. 2F). Collectively, these data demonstrated that GGPPS activity was required to promote proliferation of TSC2-null cells in vitro.

\section{Discussion}

The present immunohistochemical findings regarding p-S6 provide further evidence that the mTOR pathway is activated in RAMLs. It was also identified that GGPPS and p-S6 were expressed in RAML lesions, however GGPPS was markedly upregulated only in REA lesions. The differential expression of GGPPS between RAMLs and REAs indicated that the pathogeneses of RAML and REA are different.

It has been suggested that the mTOR signaling pathway plays an important role in AML progression and AMLs are usually associated with mutations in TSC2 $(25,26)$. The current observation of p-S6 expression in cysts was consistent with previous research. However, $\mathrm{p}-\mathrm{S} 6$ expression could not be used to distinguish RAML and REA.

Upregulation of GGPPS in REAs was observed in the present study, which indicated that GGPPS may contribute to the occurrence and progression of REAs. GGPP produced by GGPPS is essential for the geranylgeranylation of small Rho GTPases, including RhoA, Rac1, and Cdc 42 (27,28). Based on our previous study, GGPPS was primarily expressed in the cytoplasm of hepatocellular carcinomas and it was expressed at relatively high levels in HCC patients with cirrhosis (29). In addition, tumor stage, vessel invasion and tumor recurrence were closely correlated with GGPPS in terms of the diagnoses of pathological characteristics. Furthermore, Patel et al demonstrated that the activation of small Rho GTPases played a key role in the epithelial-mesenchymal transition (EMT) of renal 
Table II. Detailed clinicopathological characteristics and clinical outcomes of the REAs.

\begin{tabular}{|c|c|c|c|c|c|c|c|c|c|c|}
\hline Cases & Age & Sex & $\begin{array}{c}\text { Maximum } \\
\text { diameter }(\mathrm{cm})\end{array}$ & $\begin{array}{l}\text { Nuclear } \\
\text { atypia }\end{array}$ & Mitotic & Ki-67 & p-S6 & GGPPS & $\begin{array}{l}\text { Follow-up } \\
\text { (months) }\end{array}$ & Outcome \\
\hline 1 & 43 & M & 12 & + & - & + & + & ++ & 37 & Alive, NED \\
\hline 2 & 43 & M & 5 & - & - & + & + & ++ & 33 & Alive, NED \\
\hline 3 & 36 & $\mathrm{~F}$ & 4 & - & - & + & ++ & ++ & 33 & Alive, NED \\
\hline 4 & 23 & $\mathrm{~F}$ & 4 & - & - & - & - & ++ & 28 & Alive, NED \\
\hline 5 & 58 & M & 8 & +++ & +++ & + & - & ++ & 8 & $\begin{array}{l}\text { Dead with systemic } \\
\text { metastasis }\end{array}$ \\
\hline 6 & 44 & M & 6.5 & ++ & - & + & + & - & 24 & Alive, NED \\
\hline 7 & 35 & $\mathrm{~F}$ & 7.5 & - & - & + & + & ++ & 20 & Alive, NED \\
\hline 8 & 69 & M & 4.3 & - & - & + & ++ & ++ & 11 & Alive, NED \\
\hline 9 & 26 & $\mathrm{~F}$ & 5 & - & - & + & ++ & ++ & 17 & Alive, NED \\
\hline
\end{tabular}

Nuclear atypia $\geq 1$ is indicated with ' +', and mitosis $\geq 1$ is indicated with ' + '. REAs, renal epithelioid angiomyolipomas; GGPPS, geranylgeranyl pyrophosphate synthase; NED, no evidence of disease.
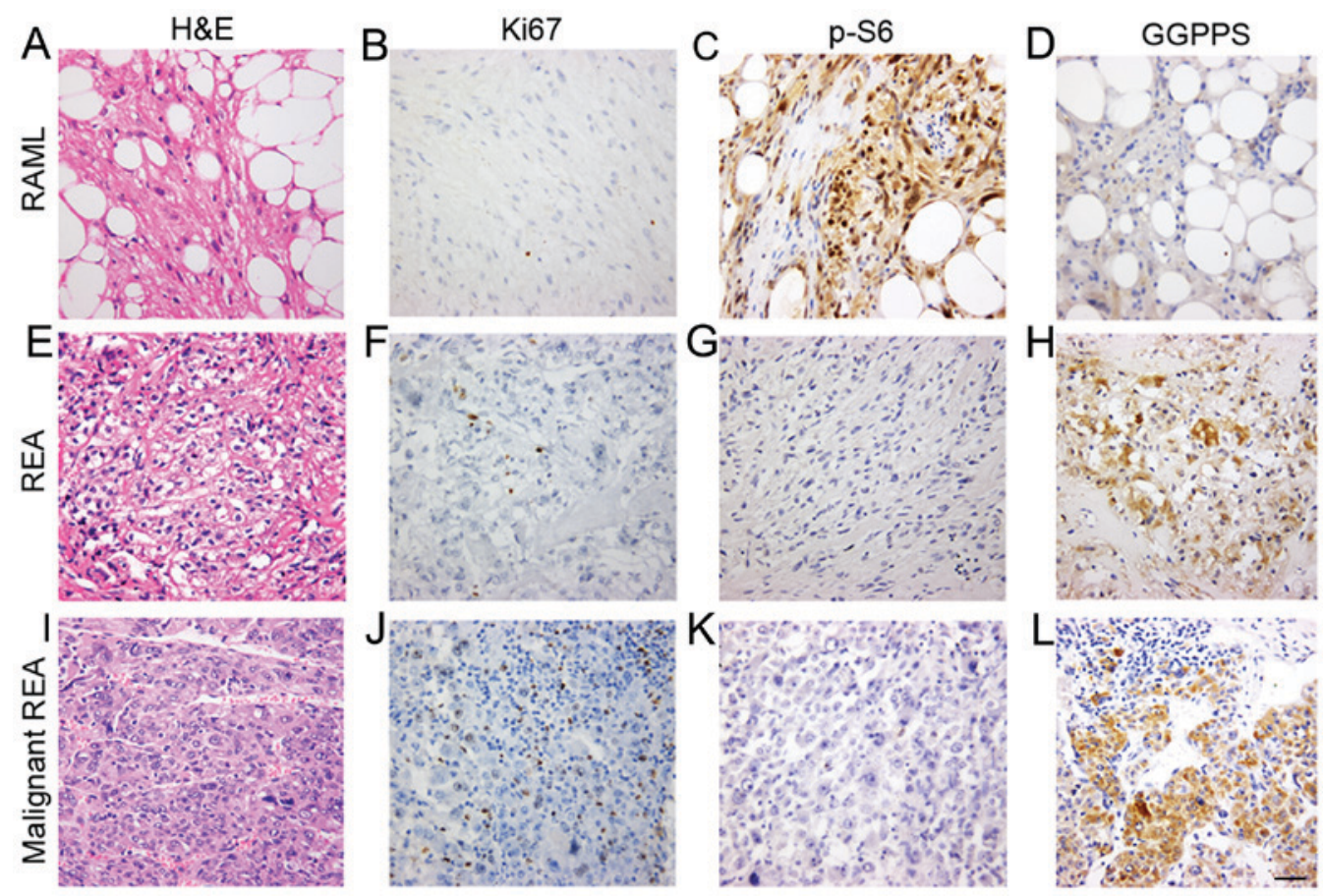

Figure 1. GGPPS is associated with the pathological characteristics of REAs. Histological features of the RAMLs, REAs and malignant REAs. (A) H\&E staining and immunostaining of the RAMLs for (B) Ki-67, (C) p-S6, and (D) GGPPS. (E) H\&E staining and immunostaining of the REAs for (F) Ki-67, (G) p-S6, and (H) GGPPS. (I) H\&E staining and immunostaining of the malignant REAs for (J) Ki-67, (K) p-S6, and (L) GGPPS. Scale bar, $50 \mathrm{~nm}$. GGPPS, geranylgeranyl pyrophosphate synthase; RAMLs, renal angiomyolipomas; REAs, renal epithelioid angiomyolipomas.

epithelial cells. EMT of renal epithelial cells led to metastasis, resulting in poor clinical outcomes $(30,31)$. In summary, these results indicated that GGPPS may be involved in epithelioid cell differentiation and may further aggravate RAMLs.

Preclinical studies have demonstrated that inhibiting the mevalonate pathway with drugs, bisphosphonates and statins leads to a decrease in tumor size (32-34). However, the effects and exact mechanism of the mevalonate pathway in AML has not yet been identified. To the best of our knowledge, this is the first study to investigate GGPPS in AMLs. It was hypothesized that the association of GGPPS with established histopathological risk factors and biochemical functions indicated that the mevalonate pathway may contribute to AML disease progression. To validate this hypothesis, the expression of GGPPS protein was evaluated in TSC2-null cells. It was revealed that the activation of mTOR may induce the accumulation of GGPPS. It was also determined that inhibition of GGPPS could induce autophagy and apoptosis.

In conclusion, immunohistochemical assays were performed to confirm the diagnosis of REA. The tumor cells were positive for HMB45, Ki-67, SMA, Melan A, p-S6 and 

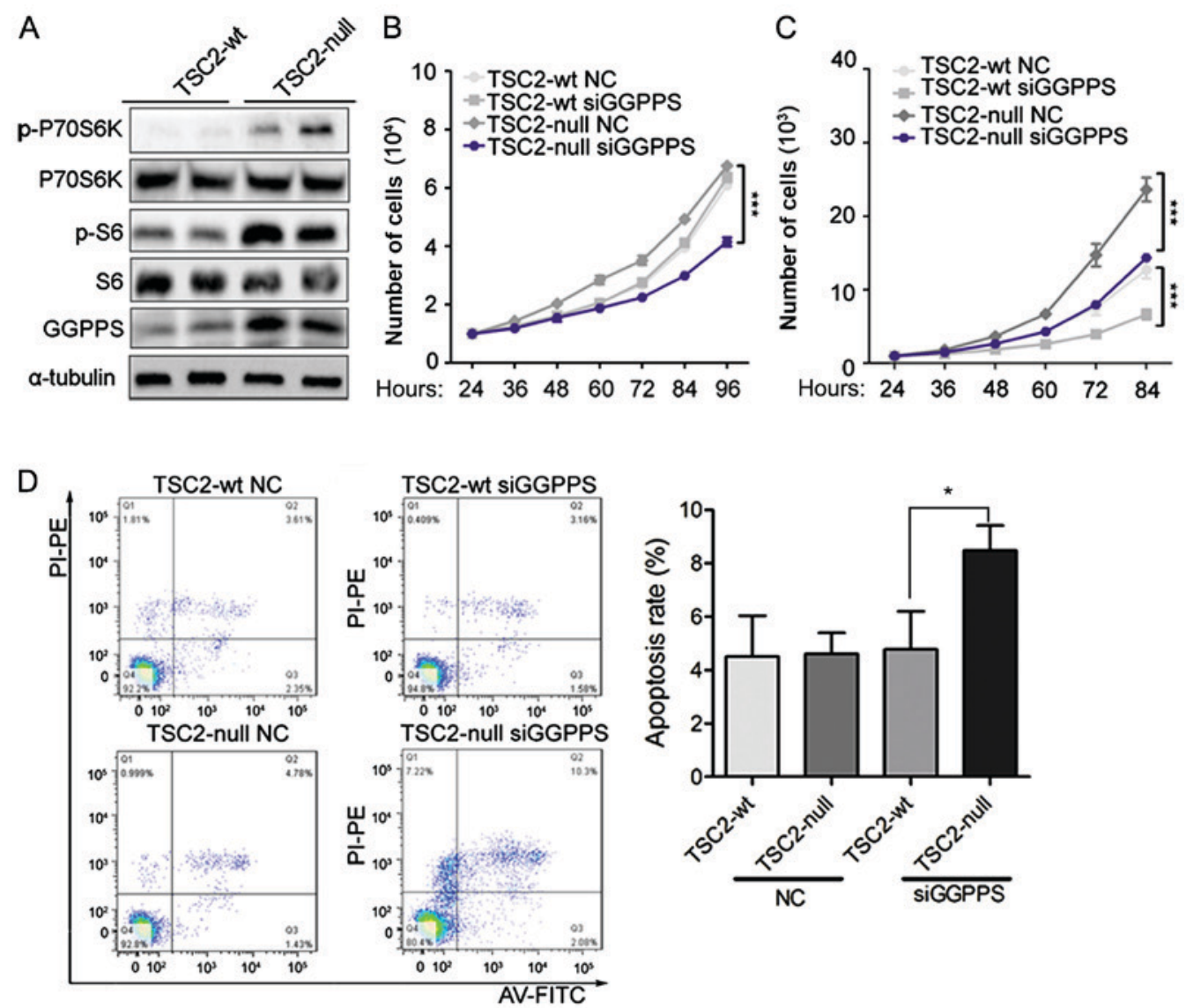

E LC3/LAMP1/DAPI
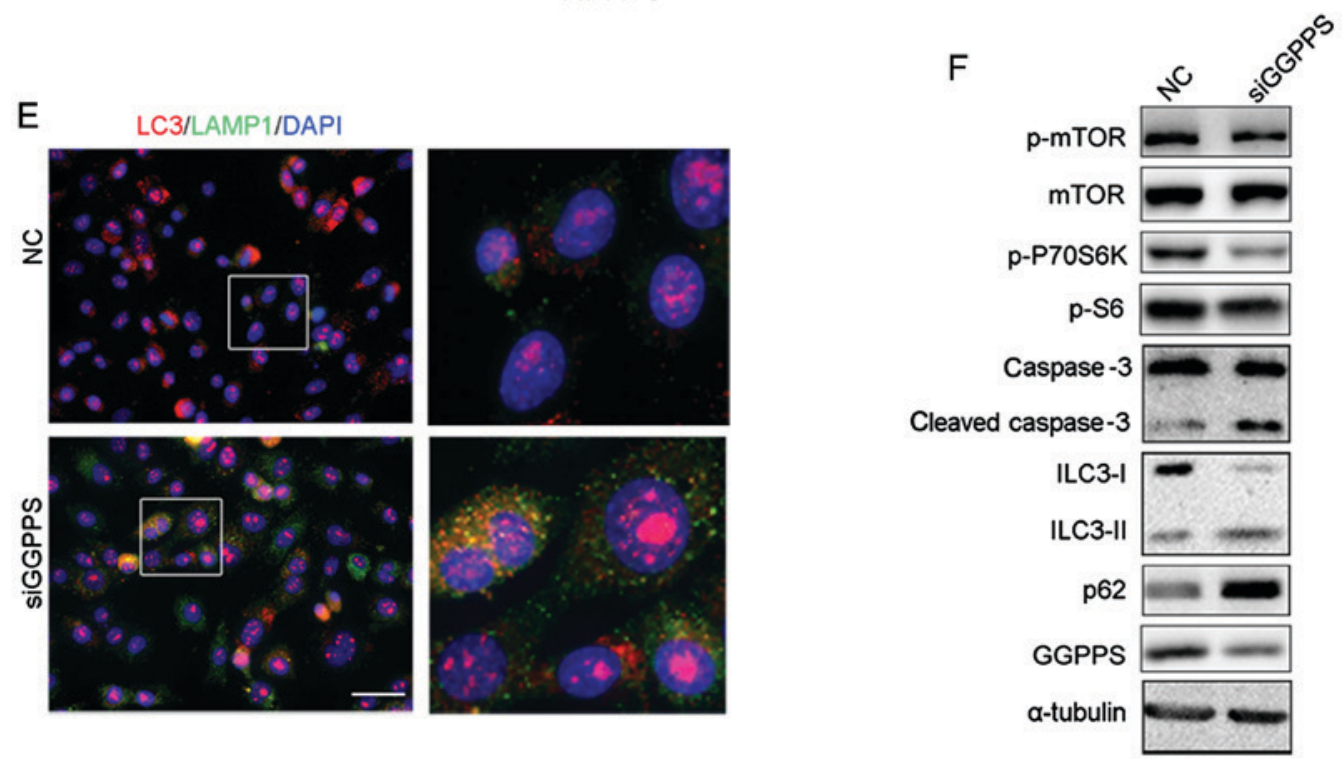

Figure 2. GGPPS is upregulated in TSC2-null cells and inhibition of GGPPS induces TSC2-null cell apoptosis. (A) Expression of GGPPS, p-S6, S6, p-P70S6K, P70S6K was analyzed by immunoblotting in TSC2-wt and TSC2-null cells. (B) Proliferation of TSC2-wt and TSC2-null cells treated with siRNA (NC, siGGPPS) for $96 \mathrm{~h}$ was analyzed by RTCA, ${ }^{* * *} \mathrm{P}<0.001$. (C) Migration of TSC2-wt and TSC2-null cells treated with siRNA (NC, siGGPPS) for $96 \mathrm{~h}$ was analyzed by RTCA, ${ }^{* * * *} \mathrm{P}<0.001$. (D) Apoptosis of TSC2-wt and TSC2-null cells treated with siRNA (NC, siGGPPS) for $72 \mathrm{~h}$ was analyzed by flow cytometry. ${ }^{*} \mathrm{P}<0.05$, as indicated. (E) LC3 and LAMP1 protein detection in TSC2-null cells treated with siRNA (NC, siGGPPS) for 3 days was analyzed by immunofluorescence. Scale bar, $50 \mathrm{~nm}$. (F) Expression of mTOR signaling pathway proteins was analyzed by immunoblotting in TSC2-null cells treated with siRNA (NC, siGGPPS) for 3 days. GGPPS, geranylgeranyl pyrophosphate synthase.

GGPPS and negative for S100 and Desmin. Furthermore, increased GGPPS expression levels were observed in REAs and TSC2-null cells, which indicated that the mevalonate pathway and geranylgeranylation may be involved in disease progression. The limitation of our study is that our hypothesis was only validated in mouse cell lines TSC2-null and
TSC2-wt. In future studies, further confirmation that the mevalonate pathway is involved in the formation of RAML in a renal angiomyolipoma cell line (SV7tert PDGF tumor-1) is required. Inhibitors of the mevalonate pathway or geranylgeranylation should also be screened for the treatment of RAML and lymphangioleiomyomatosis. 


\section{Acknowledgements}

The authors would like to thank the Department of Hepatobiliary Surgery of the Affiliated Drum Tower Hospital of Nanjing University Medical School (Nanjing, China) for the patient samples and advice on pathology evaluation.

\section{Funding}

The present study was supported by the Chinese National Science Foundation (nos. 31371373 and 31771572), the Nature Science Foundation of Jiangsu Province (no. BK20151395), and the Open Fund of State Key Laboratory of Natural Medicines (no. SKLNMKF201811). Support was also received by the Fundamental Research Funds for the Central Universities (no. 021414380330).

\section{Availability of data and materials}

The datasets used during the present study are available from the corresponding author upon reasonable request.

\section{Authors' contributions}

JC and BX conceived and designed the study. DDZ and QC collected the data and wrote the manuscript. JY interpreted the patient data regarding the renal angiomyolipomas, YLQ performed the patient data collection, KL and QS performed the histological examination of the kidney of patients by H\&E staining. YDQ and CJL contributed to the design of the project and extensive discussions. YZ and LF critically analyzed the manuscript for important intellectual content and provided technical assistance. MLJ and DCY obtained the human renal agiomyolipoma samples. SSL contributed to data analysis of flow cytometry and signaling pathway. All authors read and approved the final manuscript.

\section{Ethics approval and patient consent}

All specimen collection procedures were approved by Nanjing Drum Tower Hospital (Nanjing, China). All procedures involving human participants were in accordance with the ethical standards of the Independent Ethic Committee of Nanjing Drum Tower Hospital and with the 1964 Declaration of Helsinki and its later amendments or comparable ethical standards. Informed consent was obtained from all individual participants included in the study.

\section{Patient consent for publication}

Not applicable.

\section{Competing interests}

The authors declare that they have no competing interests.

\section{References}

1. Bader-Meunier B, Florkin B, Sibilia J, Acquaviva C, Hachulla E, Grateau G, Richer O, Farber CM, Fischbach M, Hentgen V, et al: Mevalonate kinase deficiency: A survey of 50 patients. Pediatrics 2010: e152-e159, 2011.
2. Nelson CP and Sanda MG. Contemporary diagnosis and management of renal angiomyolipoma. J Urol 168: 1315-1325, 2002.

3. Yamakado K, Tanaka N, Nakagawa T, Kobayashi S, Yanagawa M and Takeda K: Renal angiomyolipoma: Relationships between tumor size, aneurysm formation and rupture. Radiology 225: 78-82, 2002.

4. Boorjian SA, Frank I, Inman B, Lohse CM, Cheville JC, Leibovich BC and Blute ML: The role of partial nephrectomy for the management of sporadic renal angiomyolipoma. Urology 70 : 1064-1068, 2007.

5. Soulen MC, Faykus MH Jr, Shlansky-Goldberg RD, Wein AJ and Cope C: Elective embolization for prevention of hemorrhage from renal angiomyolipomas. J Vasc Interv Radiol 5: 587-591, 1994.

6. Yip SK, Tan PH, Cheng WS, Li MK and Foo KT: Surgical management of angiomyolipoma: Nephron-sparing surgery for symptomatic tumour. Scand J Urol Nephrol 34: 32-35, 2000.

7. Aydin H, Magi-Galluzzi C, Lane BR, Sercia L, Lopez JI, Rini BI and Zhou M: Renal angiomyolipoma: Clinicopathologic study of 194 cases with emphasis on the epithelioid histology and tuberous sclerosis association. Am J Surg Pathol 33: 289-297, 2009.

8. Varma S, Gupta S, Talwar J, Forte F and Dhar M: Renal epithelioid angiomyolipoma: A malignant disease. J Nephrol 24: 18-22, 2011.

9. Wolff N, Kabbani W, Bradley T, Raj G, Watumull L and Brugarolas J: Sirolimus and temsirolimus for epithelioid angiomyolipoma. J Clin Oncol 28: e65-e68, 2010.

10. Bissler JJ, McCormack FX, Young LR, Elwing JM, Chuck G, Leonard JM, Schmithorst VJ, Laor T, Brody AS, Bean J, et al: Sirolimus for angiomyolipoma in tuberous sclerosis complex or lymphangioleiomyomatosis. N Engl J Med 358: 140-151, 2008.

11. Pan CC, Chung MY, Ng KF, Liu CY, Wang JS, Chai CY, Huang SH, Chen PC and Ho DM: Constant allelic alteration on chromosome 16p (TSC2 gene) in perivascular epithelioid cell tumour (PEComa): Genetic evidence for the relationship of PEComa with angiomyolipoma. J Pathol 214: 387-393, 2008.

12. Xu N, Shen N, Wang X, Jiang S, Xue B and Li C: Protein prenylation and human diseases: A balance of protein farnesylation and geranylgeranylation. Sci China Life Sci 58: 328-335, 2015.

13. Xu N, Guan S, Chen Z, Yu Y, Xie J, Pan FY, Zhao NW, Liu L, Yang ZZ, Gao X, et al: The alteration of protein prenylation induces cardiomyocyte hypertrophy through Rheb-mTORC1 signalling and leads to chronic heart failure. J Pathol 235: 672-685, 2015.

14. Goncharova EA, Goncharov DA, Li H, Pimtong W, Lu S, Khavin I and Krymskaya VP: mTORC2 is required for proliferation and survival of TSC2-null cells. Mol Cell Biol 31: 2484-2498, 2011.

15. Wasko BM, Dudakovic A and Hohl RJ: Bisphosphonates induce autophagy by depleting geranylgeranyl diphosphate. J Pharmacol Exp Ther 337: 540-546, 2011.

16. Lin JF, Lin YC, Lin YH, Tsai TF, Chou KY, Chen HE and Hwang TI: Zoledronic acid induces autophagic cell death in human prostate cancer cells. J Urol 185: 1490-1496, 2011.

17. Burke $\mathrm{C}$ and Croteau R: Geranyl diphosphate synthase from Abies grandis: cDNA isolation, functional expression and characterization. Arch Biochem Biophys 405: 130-136, 2002.

18. Lopez-Beltran A, Scarpelli M, Montironi R and Kirkali Z: 2004 WHO classification of the renal tumors of the adults. Eur Urol 49: 798-805, 2006.

19. Lopez-Beltran A, Carrasco JC, Cheng L, Scarpelli M, Kirkali Z and Montironi R: 2009 update on the classification of renal epithelial tumors in adults. Int J Urol 16: 432-443, 2009.

20. Soslow RA, Dannenberg AJ, Rush D, Woerner BM, Khan KN, Masferrer J and Koki AT: COX-2 is expressed in human pulmonary, colonic and mammary tumors. Cancer 89: 2637-2645, 2000.

21. Ooi SM, Vivian JB and Cohen RJ: The use of the Ki-67 marker in the pathological diagnosis of the epithelioid variant of renal angiomyolipoma. Int Urol Nephrol 41: 559-565, 2009.

22. Sato K, Ueda Y, Tachibana H, Miyazawa K, Chikazawa I, Kaji S, Nojima T and Katsuda S: Malignant epithelioid angiomyolipoma of the kidney in a patient with tuberous sclerosis: An autopsy case report with p53 gene mutation analysis. Pathol Res Pract 204: 771-777, 2008.

23. Goncharova EA, Goncharov DA, Li H, Pimtong W, Lu S, Khavin I and Krymskaya VP: mTORC2 is required for proliferation and survival of TSC2-null cells. Mol Cell Biol 31: 2484-2498, 2011.

24. Kim J, Kundu M, Viollet B and Guan KL: AMPK and mTOR regulate autophagy through direct phosphorylation of Ulk1. Nat Cell Biol 13: 132-141, 2011. 
25. Smolarek TA, Wessner LL, McCormack FX, Mylet JC, Menon AG and Henske EP: Evidence that lymphangiomyomatosis is caused by TSC2 mutations: Chromosome 16p13 loss of heterozygosity in angiomyolipomas and lymph nodes from women with lymphangiomyomatosis. Am J Hum Genet 62: 810-815, 1998.

26. Coombs EJ: Role of mTOR inhibition in the treatment of patients with renal angiomyolipomas. J Am Assoc Nurse Pract 25: 588-596, 2013

27. Sinensky $M$ and Lutz RJ: The prenylation of proteins. Bioessays 14: 25-31, 1992.

28. Konstantinopoulos PA, Karamouzis MV and Papavassiliou AG: Post-translational modifications and regulation of the RAS superfamily of GTPases as anticancer targets. Nat Rev Drug Discov 6: 541-555, 2007.

29. Yu DC, Liu J, Chen J, Shao JJ, Shen X, Xia HG, Li CJ, Xue B and Ding YT: GGPPS1 predicts the biological character of hepatocellular carcinoma in patients with cirrhosis. BMC cancer 14: 248, 2014.

30. Patel S, Mason RM, Suzuki J, Imaizumi A, Kamimura T and Zhang Z: Inhibitory effect of statins on renal epithelial-to-mesenchymal transition. Am J Nephrol 26: 381-387, 2006.
31. Konosu-Fukaya S, Nakamura Y, Fujishima F, Kasajima A, McNamara KM, Takahashi Y, Joh K, Saito H, Ioritani N, Ikeda Y, et al: Renal epithelioid angiomyolipoma with malignant features: Histological evaluation and novel immunohistochemical findings. Pathol Int 64: 133-141, 2014.

32. Demierre MF, Higgins PD, Gruber SB, Hawk E and Lippman SM: Statins and cancer prevention. Nat Rev Cancer 5: 930-942, 2005.

33. Hillner BE, Ingle JN, Berenson JR, Janjan NA, Albain KS, Lipton A, Yee G, Biermann JS, Chlebowski RT and Pfister DG: American Society of Clinical Oncology guideline on the role of bisphosphonates in breast cancer. American Society of Clinical Oncology Bisphosphonates Expert Panel. J Clin Oncol 18: 1378-1391, 2000.

34. Pavlakis N and Stockler M: Bisphosphonates for breast cancer. Cochrane Database Syst Rev: CD003474, 2002.

(i) $(9)$ This work is licensed under a Creative Commons Attribution-NonCommercial-NoDerivatives 4.0 International (CC BY-NC-ND 4.0) License. 